\title{
Pemberian Informasi Obat Pasien Dengan Resep Antibiotik dan Penyediaan Antibiotik Tanpa Resep di Tangerang Selatan
}

\section{(Providing Drug Information to Patients with Prescribing Antibiotics and Provision of Antibiotics without Prescription in South Tangerang City)}

\author{
Yardi Saibi $^{{ }^{*}}$, Nelly Suryani ${ }^{1}$, Suci Ahda Novitri ${ }^{1}$, Delina Hasan ${ }^{1}$, Vidia Arlaini Anwar ${ }^{2}$ \\ ${ }^{1 *}$ Fakultas Farmasi, Universitas Islam Negeri Syarif Hidayatullah, Jakarta, Indonesia. \\ ${ }^{2}$ Akademi Farmasi IKIFA, Jakarta, Indonesia. \\ E-mail: yardi@uinjkt.ac.id
}

Article Info:

Received: 04 April 2020

in revised form: 10 Mei 2020

Accepted: 13 Juni 2020

Available Online: 06 Juli 2020

Keywords:

Pharmacists

Pharmacy technical personnel

Pharmacies

Simulated patients

Drug Information

Corresponding Author:

Yardi Saibi

Fakultas Farmasi

Universitas Islam Negeri Syarif

Hidayatullah

Jakarta

15412

Indonesia

email: yardi@uinjkt.ac.id

\begin{abstract}
A pharmacy is a place where pharmacists do their pharmaceutical work, serving directly and responsibly for patients who need their professional services. One form of direct service is the provision of drug information and counseling. The purpose of this study was to describe the drug information services provided by pharmaceutical personnel in the South Tangerang area pharmacy for patients who redeemed prescriptions using antibiotics. Patient simulation method was used to collect data to 100 pharmacies that were randomly selected based on data in the city health office. Recommendations were obtained from the South Tangerang branch of the Indonesian Pharmacists Association while ethical clearance was obtained from the ethical committee of the Faculty of Medicine, University of Indonesia. The results of this study indicate that $85 \%$ percent of pharmaceutical personnel who provide drug information for simulated patients are non-pharmacists. The most widely conveyed drug information items were the frequency of drug use delivered by $82 \%$ of pharmacists, received by the intended use (61\%) and time of use (44\%). Not related to pharmacy officers who submit the following information: drug interactions and ways to prevent them, side effects of drugs and how to prevent them; food and drinks that must be avoided as well as how to store drugs. As many as $49 \%$ of pharmacists provide additional antibiotics requested by patients without a prescription. Drug information points provided by pharmacy staff specifically by pharmacist had not been maximally delivered.
\end{abstract}

(c)

Copyright $\odot 2019$ JFG-UNTAD

This open access article is distributed under a Creative Commons Attribution (CC-BY-NC-SA) 4.0 International license.

How to cite (APA $6^{\text {th }}$ Style):

Saibi, Y., Suryani, N., Novitri, S. A., Hasan, D., Anwar, V. A. (2020). Pemberian Informasi Obat Pasien Dengan Resep Antibiotik dan Penyediaan Antibiotik Tanpa Resep di Tangerang Selatan. Jurnal Farmasi Galenika :Galenika Journal of Pharmacy (e-Journal), 6(2), 204-211. doi: 10.22487/j24428744.2020.v6.i2.15051 


\begin{abstract}
ABSTRAK
Apotek merupakan tempat apoteker melakukan pekerjaan kefarmasiannya, melayani secara langsung dan bertanggungjawab terhadap pasien yang membutuhkan jasa profesionalnya. Salah satu bentuk pelayan langsung tersebut adalah pemberian informasi obat dan konseling. Tujuan dari penelitian ini adalah untuk mendeskripsikan pelayanan informasi obat yang dilakukan oleh tenaga kefarmasian di apotek wilayah Tangerang Selatan terhadap pasien yang menebus resep yang mengandung antibiotik. Metode simulasi pasien digunakan untuk mengumpulkan data ke 100 apotek yang dipilih secara acak berdasarkan data yang ada di dinas kesehatan kota. Rekomendasi didapatkan dari Ikatan Apoteker Indonesia cabang Tangerang Selatan sementara klirens etik diperoleh dari komitre etik Fakultas Kedokteran Universitas Indonesia. Hasil penelitian ini menunjukkan bahwa $85 \%$ persen tenaga kefarmasian yang memberikan informasi obat kepada pasien simulasi adalah non apoteker. Butir informasi obat yang paling banyak disampaikan adalah frekuensi penggunaan obat yang disampaikan oleh $82 \%$ petugas apotek, diikuti oleh tujuan penggunaan $(61 \%)$ dan waktu penggunaan (44\%). Tidak satupun petugas apotek yang menyampaikan butir informasi berikut ini : interaksi obat dan cara mencegahnya, efek samping obat dan cara mencegahnya; makanan dan minuman yang harus dihindari serta cara penyimpanan obat. Sebanyak $49 \%$ petugas apotek memberikan antibiotik tambahan yang diminta oleh pasien tanpa resep. Butir-butir informasi obat yang seharusnya disampaikan oleh petugas apotek khususnya apoteker belum maksimal disampaikan.
\end{abstract}

Kata kunci: Apoteker, Tenaga teknis kefarmasian, Apotek, Pasien simulasi, Informasi Obat.

\title{
PENDAHULUAN
}

Apotek merupakan salah satu sarana pelayanan kefarmasian tempat apoteker melaksanakan praktek kefarmasian. Apoteker melaksanakan praktek kefarmasian dapat dibantu oleh apoteker lainnya, tenaga teknis kefarmasian dan juga tenaga administrasi jika diperlukan yang disesuaikan dengan kebutuhan (Peraturan Menteri Kesehatan Republik Indonesia Nomor 9 Tahun 2017 Tentang Apotek, 2017). Dalam pelaksanaan praktek kefarmasian di apotek, pemerintah telah menetapkan tolak ukur yang dapat dipergunakan sebagai pedoman oleh tenaga kefarmasian terutama apoteker dalam memberikan pelayanan kefarmasian. Terdapat dua kegiatan utama pelayanan kefarmasian menurut pedoman ini yakni : pertama kegiatan pengelolaan (sediaan farmasi, alat kesehatan dan bahan medis habis pakai); kedua adalah pelayanan farmasi klinis (Peraturan Menteri Kesehatan Republik Indonesia Nomor 73 Tahun 2016 Tentang Standar Pelayanan Kefarmasian Di Apotek, 2016). Pelayanan informasi obat dan konseling merupakan bagian dari pelayanan farmasi klinis yang harus dilakukan oleh apoteker. Melalui kegiatan ini apoteker dapat berkontribusi dalam membantu pasien untuk memahami pengobatan yang tengah mereka jalani.

Penyediaan informasi obat merupakan diantara tanggung jawab profesional yang mendasar bagi seluruh apoteker. Di era pelayanan berpusat kepada pasien saat ini, penyediaan informasi obat oleh apoteker kepada pasien menjadi bagian yang sangat penting. Kegiatan ini menuntut seorang apoteker untuk memiliki kompetensi yang tinggi, mampu mengakses sumber-sumber informasi yang terus mengalami perkembangan dengan cepat agar apoteker dapat memberikan pelayanan informasi yang tepat kepada pasien-pasien mereka (Ghaibi et al., 2015). Pemberian informasi obat terhadap pasien oleh apoteker sangat diperlukan mengingat tingkat pengetahuan pasien terhadap pengobatan yang sedang mereka jalani masih menjadi sebuah persoalan seperti yang dilaporkan oleh sejumlah penelitian berikut ini. Penelitian yang dilakukan di Sri Langka terhadap 200 orang pasien dewasa yang tengah berobat di Unit Kardiologi Rumah Sakit Nasional melaporkan bahwa pasien yang memiliki pengetahuan dengan kategori baik sebesar 17,5\% dan sisanya merupakan pasien dengan pengetahuan berkategori buruk dan cukup (Perera et al., 2012). Penelitian yang dilakukan di 35 apotek di area Lisbon Metropolitan, Portugal dengan melibatkan 633 orang pasien menemukan bahwa 82,5\% dari pasien tersebut tidak terinformasikan tentang obat yang mereka sedang gunakan. Pengetahuan pasien dengan kategori "mengetahui dengan baik" yakni untuk item indikasi obat, dosis, regimen, lama 
pengobatan dan cara pemberian (50\%) sedangkan untuk item seperti peringatan, efek samping, kontraindikasi berada di bawah $12 \%$ (Rubio et al., 2015).

Temuan serupa juga dilaporkan oleh beberapa penelitian dari beberapa wilayah di Indonesia. Penelitian yang dilakukan terhadap 342 responden yang sedang melakukan swamedikasi di tiga apotek di kota Panyabungan melaporkan bahwa hanya 20,5\% responden yang memiliki pengetahuan baik sedangkan sisanya merupakan responden dengan pengetahuan berkategori sedang dan buruk (Harahap et al., 2017). Penelitian yang dilakukan di tiga puskesmas di kota Malang terhadap pasien hipertensi menemukan bahwa $27,37 \%$ pasien memiliki pengetahuan yang baik terhadap obat yang sedang mereka gunakan sementara sisanya memiliki pengetahuan yang cukup (Pramestutie \& Silviana, 2016). Masalah rendahnya pengetahuan pasien terhadap pengobatan mereka seperti yang dilaporkan dalam sejumlah penelitian tersebut perlu menjadi perhatian oleh tenaga kesehatan terutama tenaga kefarmasian khususnya apoteker. Diketahui bahwa terdapat hubungan yang bermakna antara skor pengetahuan pasien dengan tingkat kepatuhannya menggunakan obat. (Okuyan et al., 2013). Edukasi yang diberikan oleh apoteker terkait pengobatan kepada pasien dapat meningkatkan pengetahuan pasien dan mencegah terjadinya medication error pada pasien (World Health Organization, 2016).

\section{METODE PENELITIAN}

Peneltian ini memiliki desain potong lintang dan data yang diperoleh digambarkan secara deskriptif. Data dikumpulkan dengan menggunakan metode pasien simulasi. Pendekatan ini digunakan untuk menilai kualitas pelayanan yang diberikan dan merupakan tipe observasi partisipatif. Pasien simulasi mensimulasikan situasi yang nyata untuk berpartisipasi dalam sebuah proses pemberian pelayanan. Metode ini telah digunakan secara internasional untuk menilai kualitas layanan yang diberikan oleh apotek (Foroutan \& Dabaghzadeh, 2016; Ibrahim et al., 2016; Surur et al., 2017; Watson et al., 2006). Pasien simulasi merupakan mahasiswa semester 7 dan 9 yang berjumlah 6 orang dan danggap telah memiliki bekal yang cukup untuk melakukan peran ini. Keenam pasien simulasi ini telah pernah melakukan pengumpulan data dengan metode yang sama sebelumnya. Meskipun demikian, terhadap mereka tetap diberikan pelatihan kembali untuk menyesuaikan dengan skenario yang digunakan. Skenario yang digunakan adalah pasien simulasi datang membawa resep yang bertuliskan antibiotik sefadroksil dan parasetamol untuk pengobatan infeksi saluran napas yang diderita oleh salah seorang anggota keluarganya. Sesampainya di apotek, pasien simulasi menyerahkan resep kepada petugas apotek dan mengamati proses pemberian informasi ketika obat diberikan kepada mereka. Untuk menghindari hilangnya informasi yang disampaikan oleh petugas apotek, pasien simulasi merekam secara audio proses tersebut. Pasien simulasi melakukan konfirmasi terhadap petugas apotek yang melayani mereka untuk memastikan apakah mereka sedang dilayani oleh apoteker atau bukan dengan mengajukan kalimat konfirmasi. Segera setelah pengambilan data dilakukan, pasien simulasi mengisi format yang telah dipersiapkan yang berisi butir-butir informasi obat yang seharusnya disampaikan oleh petugas apotek kepada pasien (American Society of Health System Pharmacists, 1997; Peraturan Menteri Kesehatan Republik Indonesia Nomor 73 Tahun 2016 Tentang Standar Pelayanan Kefarmasian Di Apotek, 2016). Selain menebus resep yang mengandung antibiotk, pasien simulasi juga menjalankan skenario pembelian antibiotik tanpa resep dengan menyampaikan kepada petugas apotek kalau antibiotik tersebut merupakan titipan dari anggota keluarga lainnya. pasien simulasi memperlihatkan kemasan kosong antibiotik yang ingin dibeli. Satu pasien simulasi mendatangai satu apotek dalam satu kali kunjungan. Sampel dalam penelitian ini adalah sebanyak 100 apotek di wilayah kota Tangerang Selatan yang dipilih secara acak berdasarkan data apotek yang diperoleh dari dinas kesehatan kota setempat dengan kriteria inklusi sebagai berikut : apotek terdata secara resmi pada dinas kesehatan kota; Apotek masih beroperasi pada saat dilakukan kunjungan oleh pasien simulasi. Kriteria eksklusi yakni ketika petugas apotek manyadari sedang berhadapan dengan pasien simulasi. Rekomendasi penelitian diperoleh dari Ikatan Apoteker Indonesia cabang Tangerang Selatan sementara klirens etik didapatkan dari Komite Etik Penelitian Fakultas Kedokteran Universitas Indonesia dengan nomor KET-1214/UN2.F1/ETIK/PPM.00.02/2019. Data dianalisa secara deskriptif menggunakan analisa univariat. 


\section{HASIL DAN PEMBAHASAN}

\section{Karakteristik pasien}

Sebanyak enam orang pasien simulasi telah mendatangi sebanyak 100 apotek di wilayah kota Tangerang Selatan dengan apotek target yang telah ditentukan sebelumnya untuk masing-masing pasien. Gambar 1 memperlihatkan petugas apotek yang memberikan informasi obat kepada pasien simulasi atas resep yang ditebusnya. Dapat dilihat bahwa sebanyak 15\% informasi obat atas resep diberikan oleh apoteker. Sebagian besar yakni $85 \%$ informasi obat diberikan oleh petugas apotek non apoteker. Fenomena dimana peran pemberian informasi obat atas resep yang seharusnya dilakukan oleh apoteker tetapi digantikan oleh petugas apotek non apoteker sejalan dengan beberapa penelitian yang yang lain. Penelitian yang dilakukan di wilayah Garut menemukan bahwa sebanyak 54,28\% apotek dimana pasien simulasi dilayani oleh apoteker atas resep yang ditebusnya (Suci et al., 2018). Penelitian sebelumnya di wilayah Tangerang Selatan juga melaporkan hal yang serupa yakni apoteker yang melakukan pelayanan langsung kepada pasien simulasi sebesar 36\% (Apriansyah et al., 2018). Begitupula dengan penelitian yang dilakukan di kota Banjar Baru yang menemukan bahwa tingkat kehadiran apoteker di apotek sebagai berikut : selama apotek buka $(14,29 \%)$; setiap hari kecuali hari libur (14,29\%); 2-3 kali seminggu (14,29\%); 1 x seminggu (28,57\%); dan 1 x sebulan $(28,57 \%)$. Kondisi ini tentunya berkorelasi terhadap tingginya pelayanan kefarmasian dilakukan oleh petugas non apoteker (Kartinah et al., 2015).

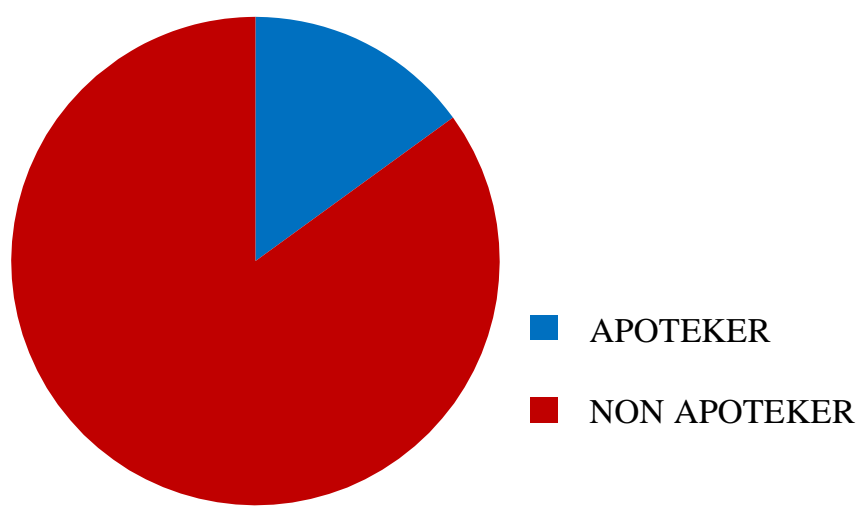

Gambar 1. Petugas apotek yang memberikan informasi obat ke pasien simulasi

Pelayanan kefarmasian merupakan pelayanan langsung dan bertanggung jawab yang diberikan oleh tenaga kefarmasian kepada pasien yang berkaitan dengan sediaan farmasi dengan tujuan untuk mencapai hasil yang pasti guna meningkatkan mutu kehidupan pasien. Pemberian informasi obat dan konseling merupakan bentuk pelayanan langsung yang diberikan oleh tenaga kefarmasian di apotek. Apotek merupakan sarana tempat apoteker melakukan praktek profesinya. Sehingga apotekerlah yang seharusnya memberikan pelayanan informasi obat atau konseling kepada pasien(Peraturan Menteri Kesehatan Republik Indonesia Nomor 73 Tahun 2016 Tentang Standar Pelayanan Kefarmasian Di Apotek, 2016; Peraturan Menteri Kesehatan Republik Indonesia Nomor 9 Tahun 2017 Tentang Apotek, 2017). Misi dari praktek kefarmasian adalah memberikan konstribusi terhadap peningkatan kesehatan dan membantu pasien terhadap masalah-masalah kesehatan yang sedang mereka alami untuk mendapatkan penggunaan yang terbaik dari obat-obatan mereka. Ada enam komponen yang terdapat dalam misi tersebut, yakni : Selalu ada untuk pasien dengan atau tanpa perjanjian; Mengidentifikasi dan menangani masalah kesehatan yang dialami oleh pasien; Melakukan promosi kesehatan; Menjamin keefektivan obat; Mencegah efek bahaya obat; Menggunakan sumber daya asuhan kesehatan yang 
terbatas secara bertanggung jawab. Butir pertama dari misi ini mensyaratkan bahwa seorang apoteker harus selalu siap di tempat prakteknya dalam hal ini apotek selama apotek tersebut ada di dalam jam operasionalnya. Ketika secara fisik apoteker ada, maka mereka siap untuk melakukan butir-butir lainnya(World Health Organization, 2011).

Butir-butir infomasi obat yang diterima oleh pasien simulasi pada saat menerima obat yang tertulis di resep disajikan pada tabel 1. Dapat dilihat bahwa butir informasi terkait frekuensi penggunaan obat paling banyak disampaikan oleh petugas apotek yakni sebesar $82 \%$ diikuti oleh tujuan penggunaan dan waktu penggunaan yang dikaitkan dengan waktu makan yang masing-masing sebesar $61 \%$ dan $44 \%$. Butir lainnya disampaikan oleh kurang atau sama dengan 30\% petugas apotek. Tidak satupun petugas apotek menyampaikan butir informasi yang terkait interaksi obat, cara mencegah interaksi obat, efek samping obat, cara mencegah efek samping obat, makanan dan minuman yang harus dihindari serta cara penyimpanan obat. Hasil penelitian ini sejalan dengan beberapa penelitian sebelumnya.

Tabel 1. Petugas apotek yang memberikan informasi obat ke pasien simulasi

\begin{tabular}{lcc}
\hline \multicolumn{1}{c}{ Pelayanan Informasi Obat } & $\begin{array}{c}\text { Jumlah petugas } \\
\text { apotek yang } \\
\text { menyampaikan }\end{array}$ & $\begin{array}{c}\text { Persentase } \\
(\boldsymbol{\%})\end{array}$ \\
\hline Tujuan Penggunaan & 61 & 61 \\
Waktu Penggunaan (sebelum/bersama/setelah & 44 & 44 \\
makan) & & \\
Frekuensi Penggunaan & 82 & 82 \\
Jumlah Obat Sekali Minum & 30 & 30 \\
Nama Obat & 31 & 31 \\
Interaksi & 0 & 0 \\
Pencegahan Intraksi & 0 & 0 \\
Efek Samping Obat & 0 & 0 \\
Pencegahan Eso & 0 & 0 \\
Makanan Dan Minuman Yang Harus Dihindari & 0 & 0 \\
Cara Penyimpanan & 0 & 0 \\
\hline
\end{tabular}

Butir-butir informasi obat di atas perlu disampaikan kepada pasien oleh apoteker secara khusus. Banyak publikasi yang melaporkan bahwa pengetahuan pasien terhadap obat yang mereka gunakan masih tergolong rendah(Harahap et al., 2017; Perera et al., 2012; Pramestutie \& Silviana, 2016; Rubio et al., 2015). Sementara pengetahuan dan pemahaman pasien tersebut menjadi salah satu faktor penting dalam menjaga kepatuhan minum obat pasien agar tinggi. Tujuan penggunaan obat penting disampaikan kepada pasien agar pasien mengerti alasan mereka menggunakan obat tersebut. Dalam kaitan dengan penggunaan antibiotik, pasien perlu diinformasikan bahwa obat yang mereka gunakan bertujuan untuk mengeliminasi bakteri yang pada saat tersebut ada dan menimbulkan masalah kesehatan di dalam tubuh mereka. Waktu penggunaan obat yang dikaitkan dengan waktu makan untuk beberapa obat perlu diperhatikan agar obat memberikan efek yang maksimal. Ada obat yang berinteraksi dengan makanan tertentu sehingga penyerapan obat bisa berkurang ataupun sebaliknya. Ada pula obat yang dianjurkan untuk digunakan bersama makanan diantaranya untuk mengurangi rasa tidak nyaman di lambung seperti untuk kasus antibiotik sefadroksil. Jumlah obat sekali minum, frekuensi penggunaan perlu disampaikan untuk diikuti oleh pasien karena ini terkait dengan kepatuhan pasien dalam mengikuti instruksi pengobatan mereka. Sefadroksil dilaporkan memiliki beberapa interaksi dengan obat lainnya yakni 3 berupa interaksi dengan level mayor dan 17 level moderat(Anonim, n.d.). Informasi terkait obat lain yang sedang digunakan oleh pasien selain dari obat yang tertulis pada resep yang sedang mereka tebus perlu digali. Interaksi obat dapat terjadi diantara obat-obat tersebut. Efek sampaing obat perlu disampaikan kepada pasien terutama efek samping yang umum terjadi termasuk cara mengatasi efek samping tersebut apabila terjadi. Pasien yang terinformasi terkait efek samping akan lebih siap dan waspada serta terhindar dari kecemasan ketika mereka mengalami efek samping suatu obat. Sefadroksil merupakan antibiotik 
beta laktam yang diketahui memiliki potensi menimbulkan reaksi alergi seperti reaksi alergi terhadap penisilin. Hal ini perlu menjadi perhatian dari tenaga kefarmasian. Cara penyimpanan perlu disampaikan kepada pasien karena obat yang disimpan dengan tidak tepat dapat menurunkan mutu obat tersebut.

Gambar 2 memperlihatkan respon petugas apotek terhadap permintaan pasien simulasi terkait antibiotik tanpa resep. Dapat dilihat bahwa sebanyak $49 \%$ petugas apotek memberikan antibiotik yang diminta oleh pasien simulasi tersebut dan sebanyak $51 \%$ petugas menyampaikan bahwa mereka hanya dapat memberikan antibiotik jika dilengkapi dengan resep dokter.

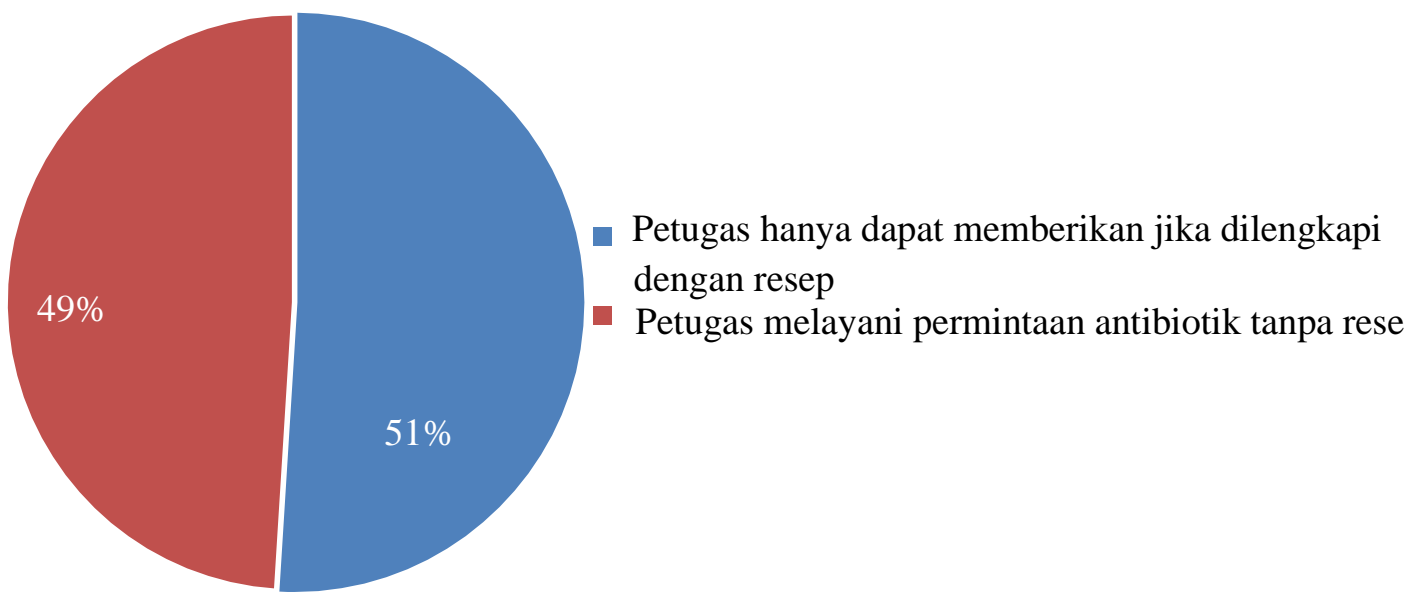

Gambar 2. Respon petugas apotek terhadap permintaan pasien simulasi atas antibiotik tanpa resep.

Penggunaan antibiotik oleh pasien tanpa resep menjadi persoalan yang dihadapi dalam dunia kesehatan dewasa ini. Temuan ini sejalan dengan temuan dari beberapa penelitian sebelumnya seperti berikut ini. Sebuah penelitian yang dilakukan di sejumlah apotek kota Surabaya menemukan bahwa sebanyak 91\% apotek memberikan antibiotik yang diminta oleh pasien tanpa dilengkapi dengan resep(Puspitasari et al., 2011). Penelitian lainnya yang dilakukan terhadap sejumlah apotek di kota Yogyakarta menemukan bahwa sebanyak $64 \%$ apotek yang menjadi sampel penelitian menjual antibiotik kepada pasien tanpa dilengkapi dengan resep dokter(Widayati et al., 2011). Antibiotik yang digunakan secara tidak tepat dan luas merupakan diantara faktor penyebab timbulnya resistensi bakteri terhadap antibiotik yang ada saat ini(National Institute of Alergy and Infectious Desease, 2011). Petugas apotek termasuk di sini apoteker dan tenaga teknis kefarmasian yang berada di bawah tanggung jawab mereka merupakan tenaga kesehatan yang diharapkan perannya dalam mengurangi atau bahkan menghentikan laju resistensi terhadap antibiotik dari bakteri patogen yang menimbulkan masalah kesehatan pada manusia. Mereka ini seharusnya dapat menghentikan perilaku penjualan antibiotik tanpa resep dan diharapkan dapat memberikan edukasi kepada masyarakt tentang resiko serta bahaya yang dapat ditimbulkan dari penggunaan antibiotik secara tidak benar.

\section{KESIMPULAN}

Pemberian informasi obat terhadap pasien yang menebus obat yang mengandung antibiotik belum sepenuhnya dilakukan oleh petugas apotek baik oleh apoteker maupun non apoteker. Ikatan apoteker Indonesia Perlu Lebih Meningkatkan pengawasannya terhadap praktek kefarmasian yang ada di wilayah kerjanya.

\section{UCAPAN TERIMA KASIH}

Terimakasih yang sebesar-besarnya kami sampaikan kepada Pusat Penelitian dan Penerbitan (Puslitpen) Universitas Islam Negeri Jakarta yang telah mendukung pendanaan penelitian ini. 


\section{DAFTAR PUSTAKA}

Al-Azzam, S. I., Al-Husein, B. A., Alzoubi, F., Masadeh, M. M., \& Al-Horani, M. A. S. (2007). Selfmedication with antibiotics in Jordanian population. International Journal of Occupational Medicine and Environmental Health, 20(4), 373-380. https://doi.org/10.2478/v10001-0070038-9

American Society of Health-System Pharmacists. (1997). Guidelines on pharmacist-conducted patient education and counseling. American Journal of Health-System Pharmacy, 54(4), 431-434.

Anonim. (n.d.). Cefadroxil. Retrieved April 3, 2020, from https://www.drugs.com/ppa/cefadroxil.html

Apriansyah, A., Saibi, Y., \& Karyadi. (2018). Clinical Pharmacy Service At Community Pharmacy In South Tangerang Regency. Journal of Pharmacopolium, 1(2), 81-87.

Fernandez, B. A. M. (2013). Study of the Use of Non-Prescription Antibiotics in the Districts of Manggarai and West Manggarai - NTT. Jurnal Ilmiah Mahasiswa Universitas Surabaya, 2(2), 1-17.

Foroutan, N., \& Dabaghzadeh, F. (2016). Evaluating the practice of iranian community pharmacists regarding oral contraceptive pills using simulated patients. Pharmacy Practice, 14(4), 1-7. https://doi.org/10.18549/PharmPract.2016.04.745

Ghaibi, S., Ipema, H., \& Gabay, M. (2015). ASHP guidelines on the pharmacist's role in providing drug information. American Journal of Health-System Pharmacy, 72(7), 573-577. https://doi.org/10.2146/sp150002

Harahap, N. A., Khairunnisa, K., \& Tanuwijaya, J. (2017). Patient knowledge and rationality of self - medication in three pharmacies of Panyabungan City, Indonesia. Jurnal Sains Farmasi \& Klinis, 3(2), 186. https://doi.org/10.29208/jsfk.2017.3.2.124

Ibrahim, M. I. B. M., Palaian, S., Al-Sulaiti, F., \& El-Shami, S. (2016). Evaluating community pharmacy practice in Qatar using simulated patient method: Acute gastroenteritis management. Pharmacy Practice, 14(4). https://doi.org/10.18549/PharmPract.2016.04.800

Kartinah, N., Annisa, S., Yuniarti, T., Setyanto, H., Mangkurat, U. L., Yani, J. A., Banjarbaru, K., Rangas, P. S., Barat, M., \& Banjar, K. (2015). Gambaran Pelayanan Kefarmasian di Apotek Wilayah Kota Banjarbaru Berdasarkan Standar Pelayanan Kefarmasian. Seminar Nasional \& Workshop Perkembangan Terkini Sains Farmasi Dan Klinik 5, 245-251. http://semnasffua.com/2015/wp-content/uploads/2013/09/34.pdf

Peraturan Menteri Kesehatan Republik Indonesia Nomor 73 Tahun 2016 Tentang Standar Pelayanan Kefarmasian Di Apotek, Pub. L. No. 73, 331 (2016).

Peraturan Menteri Kesehatan Republik Indonesia Nomor 9 Tahun 2017 Tentang Apotek, Pub. L. No. 9, 1 (2017).

Llor, C., \& Cots, J. (2009). The sale of antibiotics without prescription in pharmacies in Catalonia, Spain. Clin Infet Dis, 48(10), 20-29.

National Institute of Alergy and Infectious Desease. (2011). Causes of Antimicrobial (Drug) Resistance. https://www.niaid.nih.gov/research/antimicrobial-resistance-causes 
Okuyan, B., Sancar, M., \& Izzettin, F. V. (2013). Assessment of medication knowledge and adherence among patients under oral chronic medication treatment in community pharmacy settings. Pharmacoepidemiology and Drug Safety, 22(2), 209-212. https://doi.org/10.1002/pds.3275

Perera, T., Ranasinghe, P., Perera, U., Perera, S., Adikari, M., Jayasinghe, S., \& Constantine, G. R. (2012). Knowledge of prescribed medication information among patients with limited English proficiency in Sri Lanka. BMC Research Notes, 5, 658. https://doi.org/10.1186/1756-0500-5658

Pramestutie, H. R., \& Silviana, N. (2016). The Knowledge Level of Hypertension Patients for Drug Therapy in the Primary Health Care of Malang. Indonesian Journal of Clinical Pharmacy, 5(1), 26-34. https://doi.org/10.15416/ijcp.2016.5.1.26

Puspitasari, H. P., Faturrohmah, A., \& Hermansyah, A. (2011). Do Indonesian community pharmacy workers respond to antibiotics requests appropriately? Tropical Medicine and International Health, 16(7), 840-846. https://doi.org/10.1111/j.1365-3156.2011.02782.x

Rubio, J. S., García-Delgado, P., Iglésias-Ferreira, P., Mateus-Santos, H., \& Martínez-Martínez, F. (2015). Measurement of patients' knowledge of their medication in community pharmacies in Portugal. Ciência \& Saúde Coletiva, 20(1), 219-228. https://doi.org/10.1590/141381232014201.20952013

Suci, R. P., Saibi, Y., \& Dasuki, A. (2018). Kualitas Pelayanan Informasin Obat ( Konseling ) di Apotek Kabupaten Garut. Jurnal Pharmascience, 05(01), 1-7.

Surur, A. S., Getachew, E., Teressa, E., Hailemeskel, B., Getaw, N. S., \& Erku, D. A. (2017). Self - reported and actual involvement of community pharmacists in patient counseling: A crosssectional and simulated patient study in Gondar, Ethiopia. Pharmacy Practice, 15(1), 1-7. https://doi.org/10.18549/PharmPract.2017.01.890

Watson, M., Norris, P., \& Granas, A. (2006). A systematic review of the use of simulated patients and pharmacy practice research. International Journal of Pharmacy Practice, 14(2), 83-93. https://doi.org/10.1211/ijpp.14.2.0002

WHO. (2014). Antimicrobial resistance. Global report on surveillance. In World Health Organization (Vol. 61, Issue 3). https://doi.org/10.1007/s13312-014-0374-3

Widayati, A., Suryawati, S., de Crespigny, C., \& Hiller, J. E. (2011). Self medication with antibiotics in Yogyakarta City Indonesia: a cross sectional population-based survey. BMC Research Notes, 4(1), 491. https://doi.org/10.1186/1756-0500-4-491

World Health Organization. (2011). Joint FIP / WHO guidelines on good pharmacy practice: standards for quality of pharmacy services. WHO Technical Report Series, No. 961, 1-18.

World Health Organization. (2016). Medication errors. In World Health Organisation (Vol. 30, Issue 35). World Health Organization. https://doi.org/10.7748/ns.30.35.61.s49 